\title{
Tetrahydroisoquinolines as Orexin Receptor Antagonists: Strategies for Lead Optimization by Solution-Phase Chemistry
}

Ralf Koberstein*, Hamed Aissaoui, Daniel Bur, Martine Clozel, Walter Fischli, François Jenck, Celia Mueller, Oliver Nayler, Thierry Sifferlen, Alexander Treiber, and Thomas Weller

\begin{abstract}
Different techniques can be applied for the automated production of small and large compound collections. Large libraries that are often generated and tested during the lead-finding stage of a project are typically produced by solid-phase chemistry. Libraries that are significantly smaller in size are often synthesized in solution. Chemistry in solution is rather versatile, offers numerous advantages and is therefore often the method of choice for generating small libraries during a lead optimization process. Fast and reliable purification procedures are required to yield compounds of high quality that can be immediately used in biological as well as pharmacological assays. Solution-phase chemistry combined with automated purification was applied to optimize initial lead inhibitors for the two human orexin receptors OX1 and OX2. Starting from a submicro-molar OX1 selective lead compound, low nanomolar analogues with improved physico-chemical properties were synthesized that antagonize either one or both orexin receptors.
\end{abstract}

Keywords: Automated purification · Lead optimization · Orexin receptor · Solution-phase chemistry · Tetrahydroisoquinoline

\section{Introduction}

Automation of processes in chemistry and particularly in pharmaceutical research is of increasing importance to improve productivity. An important means is therefore combinatorial chemistry that has experienced a significant paradigm shift from large libraries with low quality to smaller numbers of compounds with high quality [1]. One important aspect of quality is purity of the individual compounds of the library, others are diversity, druglikeness

${ }^{\star}$ Correspondence: Dr. R. Koberstein

Actelion Pharmaceuticals Ltd

Gewerbestrasse 16

$\mathrm{CH}-4123$ Allschwil

Tel.: +41614874559

Fax: +41614874500

E-Mail: ralf.koberstein@actelion.com or ease of production [2]. A small focused library of well-purified compounds that has been synthesized in two weeks may be of substantially more value than a huge one needing six month for completion.

In principle libraries can be produced either on solid phase or by chemistry in solution [3]. Solid-phase chemistry is attractive with respect to the large number of compounds synthesized in parallel and the number of reaction steps that can be performed sequentially without difficult purification of intermediates. This technique suffers from very time-consuming optimizations of reaction conditions and the limited number of feasible reactions available. A crucial step is the purification of the final products.

\section{Strategy}

Having different techniques for library production at hand, one of the key tasks for a chemist is to select the optimal one for a given problem [4]. Initial lead-finding procedures normally require the screening of huge compound collections that are often synthesized by solid-phase chemistry whereas optimizing lead compounds can be achieved faster by applying parallel chemistry in solution. This is mainly due to the better quality data obtained with purified compounds leading to convincing structure-activity and structure-property relationships [5]. As long as it is not possible to reliably predict in vitro as well as in vivo activity, ADME properties [6] or bloodbrain-barrier penetration, fast and accurate generation of experimental data is absolutely crucial for success. In light of the various aspects discussed above we at Actelion have decided to concentrate on small focused libraries produced by automated solution-phase chemistry in order to optimize properties of initial lead compounds. Large compound collections screened for initial lead finding are either obtained from commercial sources or from collaborations with external partners. 


\section{Library Production}

Production of a solution phase library can be divided in four sequential steps: 1 ) preparation of starting materials, 2) synthesis of compounds, 3) purification, and 4) analysis. In order to deal efficiently with these demands Actelion has built up a complete system of parallel chemistry facilities. As already mentioned some of the appealing advantages of solution-phase parallel chemistry are the high number of different chemical reactions possible as well as the versatility of conditions and flasks that are used. In standard procedures we use simple capped glass vials in $4 \times 6$-formatted racks. Four of these racks can be shaken and/or heated on a Büchi Syncore. When special conditions are required we use a computercontrolled synthesizer from Chemspeed, which allows the use of inert conditions in a temperature range from -40 to $+140{ }^{\circ} \mathrm{C}$ (Fig. 1).

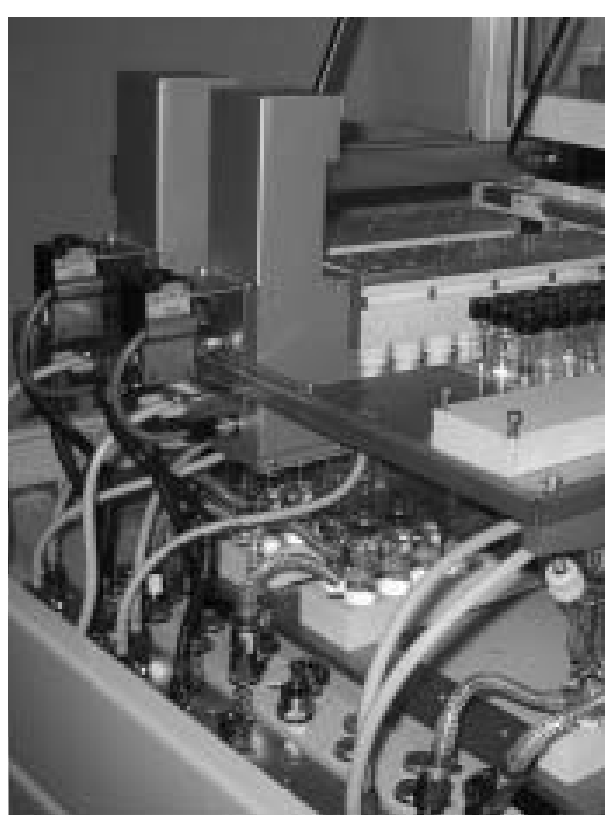

Fig. 1. Chemspeed ASW 2000
Automation of the purification process is crucial in order to obtain high-quality compounds in a short time. There is no methodology available yet that generally allows parallel purification of dozens of compounds in a high-throughput procedure. Therefore, purification is by far the most time-consuming step of a library production and has to be optimized as much as possible [5b][7]. We use an automated HPLC system that is capable of purifying a sample in the 10-100 $\mathrm{mg}$ range within 6 min (Fig. 2). A standard set-up allows baseline separation of more than $95 \%$ of all samples (Fig. 3). Cycle times can be reduced to less than 4 min for easily separable reaction mixtures. Our purification system is connected to an autosampler and can be triggered by either UV- or light scattering detectors. The collected fractions are analyzed by HPLC-MS ( 2.5 min cycle time) in order to identify those containing the desired products.

Efficient library synthesis usually requires the help of complex software tools. Actelion has programmed an in-house software that allows easy management of all data produced during synthesis. It includes features for planning and administrating libraries such as the generation of virtual libraries, application of several filter tools related to compound properties and library diversity, visualization of data, management of electronic protocols and last but not least automated registration of final products.

\section{Building Blocks}

One of the major disadvantages of solution-phase chemistry is the limited number of reaction steps that can be performed successively without purification procedures. Synthesis of suitable building blocks very often requires much more time than the ac-

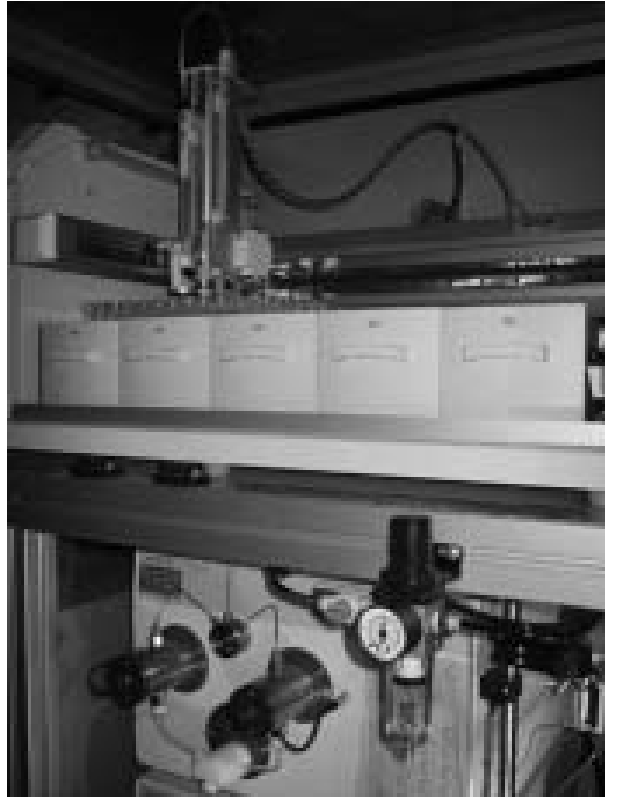

Fig. 2. Automated Prep. HPLC

tual production of the library. The obvious solution to this problem is to synthesize the templates in parallel as well. This requires automated purification of compounds on a gram scale. We have set up a preparative HPLC system to purify up to $5 \mathrm{~g}$ of material within $30 \mathrm{~min}$.

\section{Orexin Project - A Case Study}

Two peptides called orexin A and orexin B were discovered in 1998 [8]. They are produced in discrete neurons of the lateral hypothalamus and bind to two G-proteincoupled receptors named orexin 1 (OX1) and orexin 2 (OX2) respectively. Whereas orexin A, a 33 amino acid neuropeptide, binds to both receptors with high affinity $\left(\mathrm{IC}_{50}(\mathrm{OX} 1)=20 \mathrm{nM}, \mathrm{IC}_{50}(\mathrm{OX} 2)=36 \mathrm{nM}\right)$, orexin $\mathrm{B}$, a 28-mer, is OX2 selective $\left(\mathrm{IC}_{50}(\mathrm{OX} 1)=420 \mathrm{nM}, \quad \mathrm{IC}_{50}(\mathrm{OX} 2)=\right.$ $38 \mathrm{nM}$ ) [8b]. Orexins are believed to have
Fig. 3. UV chromatograms of a crude reaction mixture (left) and of the corresponding product after purification by preparative HPLC (right)
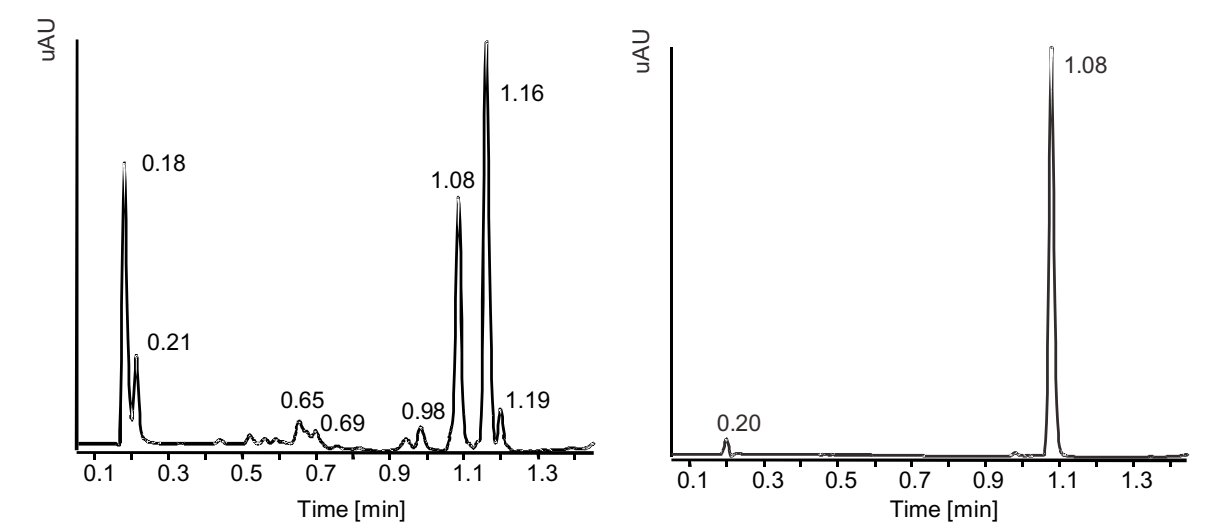
a predominant role in regulation of appetite and food intake since initial reports mentioned increased food and water uptake after orexin application to brains of rats. However, nerve fibers reacting to orexin stimuli are far reaching in the brain, suggesting that orexins might have multiple functions, in particular as regulators of sleep and wake states [9]. These and other findings led to the conclusion that the orexin system might be an interesting target [10].

A high-throughput screening was carried out with compounds obtained from an external partner. Initial activity was determined in Chinese hamster ovary $(\mathrm{CHO})$ cells overexpressing human OX1 and OX2 receptors respectively using a FLIPR [11] based calcium assay [12]. Compound $\mathbf{1}$ (Table 1) could be identified as a lead structure and a chemical program was started to find derivatives with higher affinity, suitable physico-chemical properties and various selectivity specifications [13]. Unless otherwise specified, all compounds reported in this article are racemic mixtures.

\subsection{Optimization of the Amide Part of Compound 1}

In a first step modifications of the amide part of compound $\mathbf{1}$ were carried out. More than 100 amides were obtained in a one-pot procedure by successive addition of the respective amine and tetrahydropapaverine to a solution of bromoacetyl bromide and $\mathrm{N}, \mathrm{N}$-diisopropylethyl-amine in THF. In comparison to the benzylamide $\mathbf{1}$ aniline derivatives like $\mathbf{2}$ or compounds with an elongated substituent like $\mathbf{3}$ were much less active on the OX1 receptor (Table 1). The same is true for tertiary amides $(\mathbf{5}, \mathbf{6})$ and the saturated analogue 11. Unfortunately, improved affinity could be observed neither with picolylamides $\mathbf{7}, \mathbf{8}$, and $\mathbf{9}$ nor with isoxazole $\mathbf{1 0}$. Also none of the newly synthesized analogues bearing one or more alkyl-, alkoxy- or halogen substituents at the aromatic ring $\left(\mathrm{HNR}^{1} \mathrm{R}^{2}=\right.$ benzyl) were superior to 1 . In contrast to the 2-aminoindane derivative $\mathbf{1 3}$ which showed a slightly improved binding to $\mathrm{OX} 2$ the corresponding 1 -aminoindane analogue $\mathbf{1 2}$ is highly active on OX1. To explore these indanylamides in more detail 20 new derivatives were prepared with $\mathbf{1 4}$ showing affinities comparable to those measured for the natural ligands.

\subsection{Optimization of the 3,4- Dimethoxybenzyl Fragment of Compound 1}

In a second step we intended to introduce new substituents in position 1 of the tetrahydroisoquinoline moiety. The synthesis of the required templates is straight-

Table 1. Optimization of the amide part of compound 1<smiles>COc1ccc(CC2NCCc3cc(OC)c(OC)cc32)cc1OC</smiles>

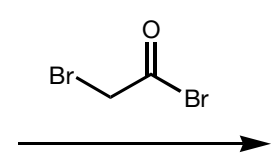

$H N R^{1} R^{2}$<smiles>CCCNC(=O)CN1CCc2cc(OC)c(OC)cc2C1Cc1ccc(OC)c(OC)c1</smiles>

Tetrahydropapaverine

\begin{tabular}{|c|c|c|c|}
\hline Compound & Amine $\left(H N R^{1} R^{2}\right)$ & $\begin{array}{c}\mathrm{OX} 1 \\
\mathrm{IC}_{50}[\mathrm{nM}] \\
\end{array}$ & $\begin{array}{c}\mathrm{OX} 2 \\
\mathrm{IC}_{50}[\mathrm{nM}]\end{array}$ \\
\hline 1 & benzylamine & 119 & 8152 \\
\hline 2 & aniline & 4771 & $>10000$ \\
\hline 3 & phenethylamine $^{a}$ & 3138 & $>10000$ \\
\hline 4 & $\alpha$-methylbenzylamine & 200 & 9499 \\
\hline 5 & $N$-benzyl- $N$-methylamine & 2008 & $>10000$ \\
\hline 6 & tetrahydroisoquinoline & $>10000$ & $>10000$ \\
\hline 7 & 2-(aminomethyl)pyridine & 690 & $>10000$ \\
\hline 8 & 3-(aminomethyl)pyridine & 268 & $>10000$ \\
\hline 9 & 4-(aminomethyl)pyridine & 1138 & $>10000$ \\
\hline 10 & 5-(aminomethyl)isoxazole & 731 & $>10000$ \\
\hline 11 & cyclohexylmethylamine & 1565 & $>10000$ \\
\hline 12 & 1-aminoindane & 49 & 679 \\
\hline 13 & 2-aminoindane & 129 & 1098 \\
\hline 14 & 6-methoxy-indan-1-ylamine & 19 & 101 \\
\hline
\end{tabular}

Note: unless otherwise specified (see entry 3), all compounds reported in this article are racemic mixtures

aEnantiomerically pure compound (1S-configurated tetrahydropapaverine; the corresponding enantiomer is inactive on both receptors)

forward (Scheme 1). Starting from homoveratrylamine the respective tetrahydroisoquinolines can be synthesized via the amides by a Bischler-Napieralski reaction and purified by crystallizing the respective hydrochloride salts (Table 2). Interestingly, the removal of one or two of the methoxy groups from the benzyl substituent $(\mathbf{1 5}, \mathbf{1 6}$, $17,22,23,24)$ led to a significant decrease of activity on OX1. The same is true for the piperonyl derivatives $\mathbf{1 8}$ and $\mathbf{2 5}$, suggesting an important anchor function for the 3,4-dimethoxybenzyl substituent due to a preferred conformation with both methoxy groups being in plane with the aromatic ring (Scheme 2).

Replacing methoxy groups with different halogens showed that fluorine substituents are detrimental $(\mathbf{1 9}, \mathbf{2 0}, \mathbf{2 6})$ even if the mono fluorinated product $\mathbf{1 9}$ is superior to compound $\mathbf{1 7}$ that lacks a substituent in the 3-position. In contrast, the dichlorosubstituted analogue 27 yields affinities comparable to those of $\mathbf{1}$ on OX1 and increased affinity on OX2. High affinities for the OX1 were also found for the $o$-xylene derivatives $\mathbf{2 1}$ and $\mathbf{2 8}$ and the pyrimidine analogue 29. 


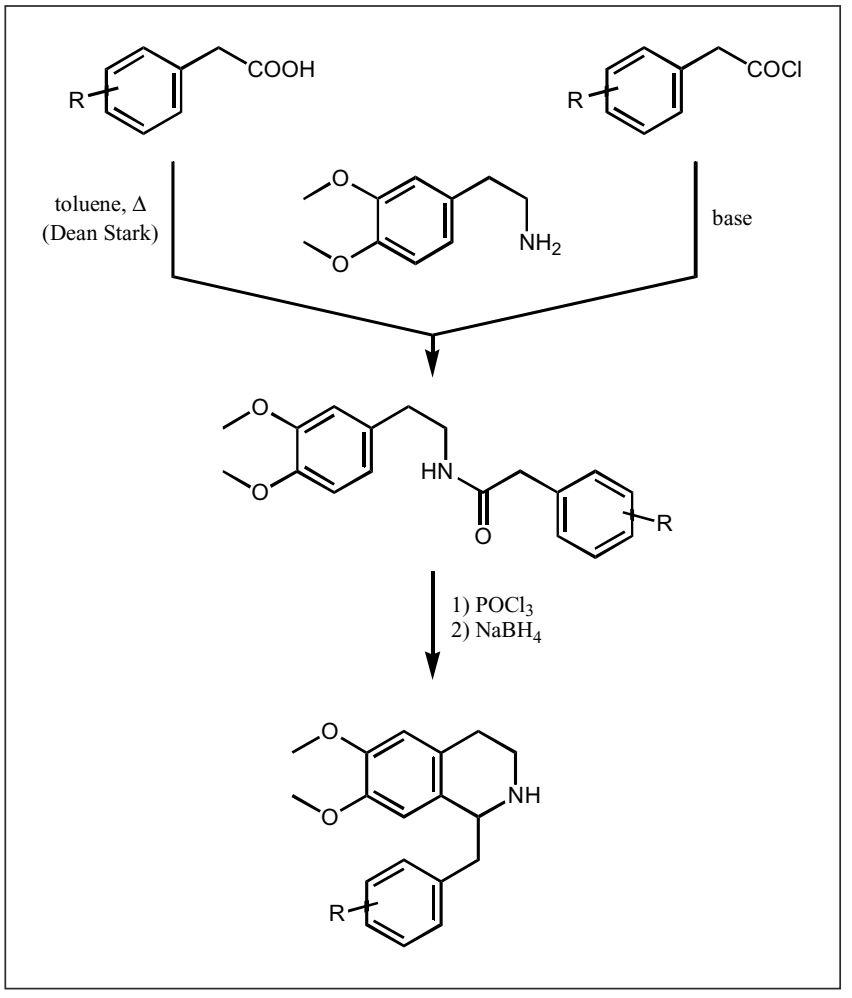

Scheme 1. Synthesis of tetrahydroisoquinolines

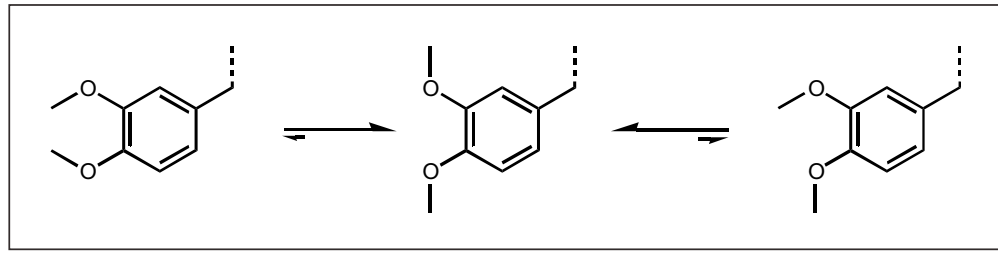

Scheme 2. 3,4-Dimethoxybenzyl substituents - preferred conformations
Table 2. Optimization of the 3,4-dimethoxybenzyl fragment of compound 1

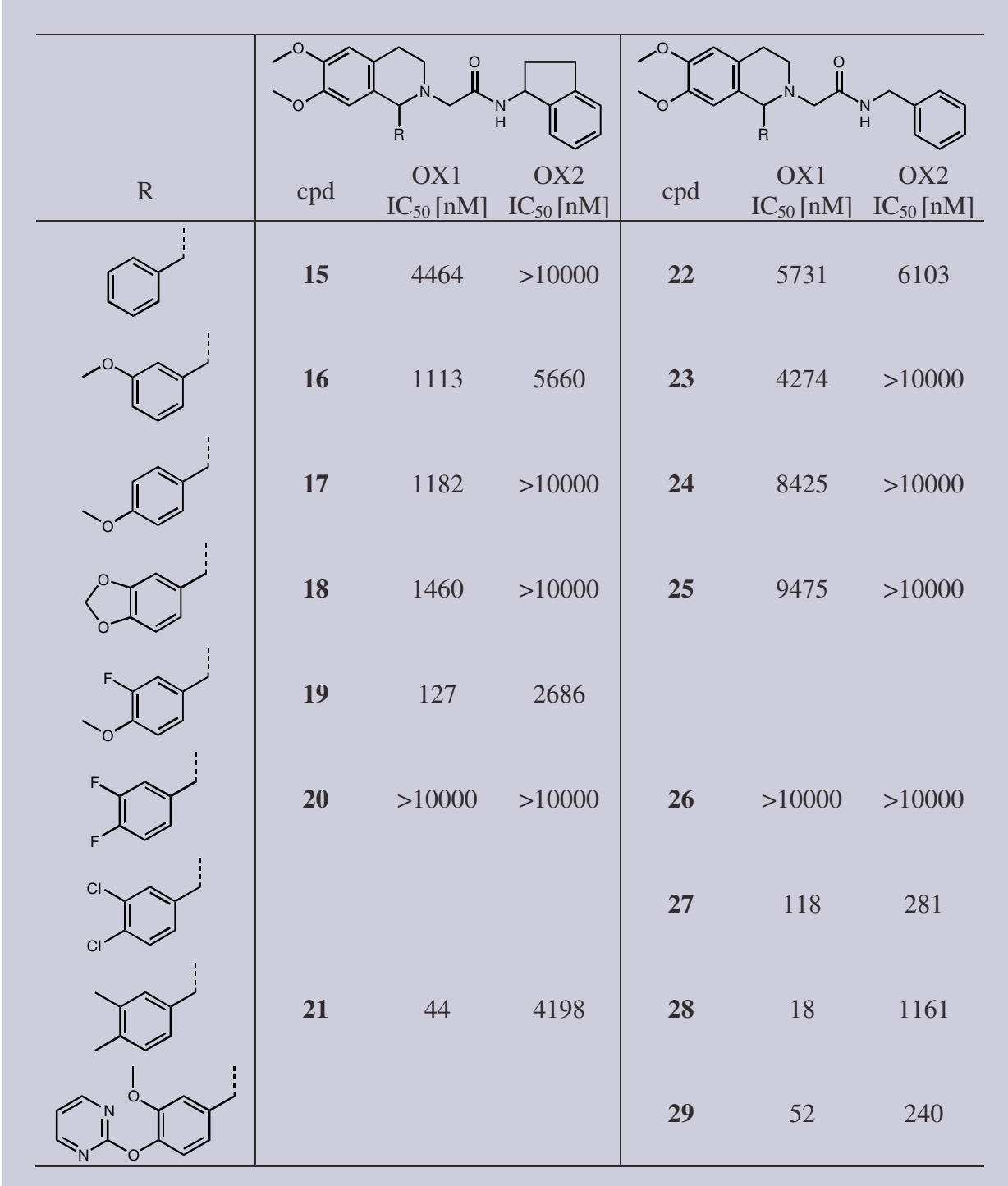

\subsection{Optimization of the}

\section{Tetrahydroisoquinoline Part}

All compounds described so far showed higher activity on OX1 compared to OX2. Some were completely inactive on OX2. However, we were also aiming to obtain compounds with high OX2 affinity. Therefore, more than 50 different analogues of compound 1 were synthesized which differ only in the 6,7-substitution pattern of the tetrahydroisoquinoline core structure (Table 3). It turned out that even small structural modifications led to dramatic changes in activity. Removal of the methoxy group in position 7 (compound 30) is just as detrimental as a ring closure leading to methylenedioxy compounds $\mathbf{3 4}$ and $\mathbf{3 7}$. Replacement of the 6-methoxy group as present in $\mathbf{1}$ by a more voluminous ethoxy substituent led to inactive $\mathbf{3 3}$ whereas bulky substituents are better tolerated in the 7-position (compounds $\mathbf{3 1}$ and $\mathbf{3 2}$ ).

Substituting the benzyl group of compound $\mathbf{3 2}$ by a picolyl moiety decreased affinity on OX1 (36). A similar effect was already observed in compound 7 (compared to 1). Shifting the substituents from position 6 and 7 to positions 5 and 8 yielded compounds highly selective for OX2 $\left(\mathbf{3 8}, \mathrm{IC}_{50}=177 \mathrm{nM}\right)$. Subsequently we tried to further optimize the activity on OX2. A chain elongation in position 5 led to less active compounds (e.g. $\mathrm{R}^{1}=\mathrm{EtO}, \mathbf{4 0}$ ) whereas a 7 -fold increase in activity could be obtained by substituting the methoxy group in position 8 by an ethoxy group $\left(39, \mathrm{IC}_{50}(\mathrm{OX} 2)=26 \mathrm{nM}\right)$. 
Table 3. Optimization of the tetrahydroisoquinoline part of compound 1<smiles>[2H]c1[13cH]c([2H])c2c(c1[2H])C(Cc1ccc(OC)c(OC)c1)N(CC(=O)N[Tl])CC2</smiles>

\begin{tabular}{|c|c|c|c|c|c|c|c|c|c|}
\hline $\mathrm{R}^{1}$ & $\mathrm{R}^{2}$ & $\mathrm{R}^{3}$ & $\mathrm{R}^{4}$ & cpd & $\begin{array}{c}\mathrm{OX} 1 \\
\mathrm{IC}_{50}[\mathrm{nM}]\end{array}$ & $\begin{array}{c}\mathrm{OX} 2 \\
\mathrm{IC}_{50}[\mathrm{nM}]\end{array}$ & cpd & $\begin{array}{c}\text { OX1 } \\
\mathrm{IC}_{50}[\mathrm{nM}] \\
\end{array}$ & $\begin{array}{c}\mathrm{OX} 2 \\
\mathrm{IC}_{50}[\mathrm{nM}]\end{array}$ \\
\hline $\mathrm{H}$ & $\mathrm{MeO}$ & $\mathrm{MeO}$ & $\mathrm{H}$ & 1 & 119 & 8152 & 7 & 690 & $>10000$ \\
\hline $\mathrm{H}$ & $\mathrm{MeO}$ & $\mathrm{H}$ & $\mathrm{H}$ & 30 & 5607 & 3691 & & & \\
\hline $\mathrm{H}$ & $\mathrm{MeO}$ & EtO & $\mathrm{H}$ & 31 & 33 & $>10000$ & & & \\
\hline $\mathrm{H}$ & $\mathrm{MeO}$ & $i-\mathrm{PrO}$ & $\mathrm{H}$ & 32 & 17 & $>10000$ & 36 & 155 & $>10000$ \\
\hline $\mathrm{H}$ & EtO & $\mathrm{MeO}$ & $\mathrm{H}$ & 33 & 1140 & $>10000$ & & & \\
\hline $\mathrm{H}$ & \multicolumn{2}{|c|}{$\mathrm{O}-\mathrm{CH}_{2}-\mathrm{O}$} & $\mathrm{H}$ & 34 & $>10000$ & $>10000$ & 37 & $>10000$ & $>10000$ \\
\hline $\mathrm{MeO}$ & $\mathrm{H}$ & $\mathrm{H}$ & $\mathrm{MeO}$ & 35 & $>10000$ & 1105 & 38 & $>10000$ & 177 \\
\hline $\mathrm{MeO}$ & $\mathrm{H}$ & $\mathrm{H}$ & EtO & & & & 39 & 5102 & 26 \\
\hline EtO & $\mathrm{H}$ & $\mathrm{H}$ & $\mathrm{MeO}$ & & & & 40 & $>10000$ & 545 \\
\hline
\end{tabular}

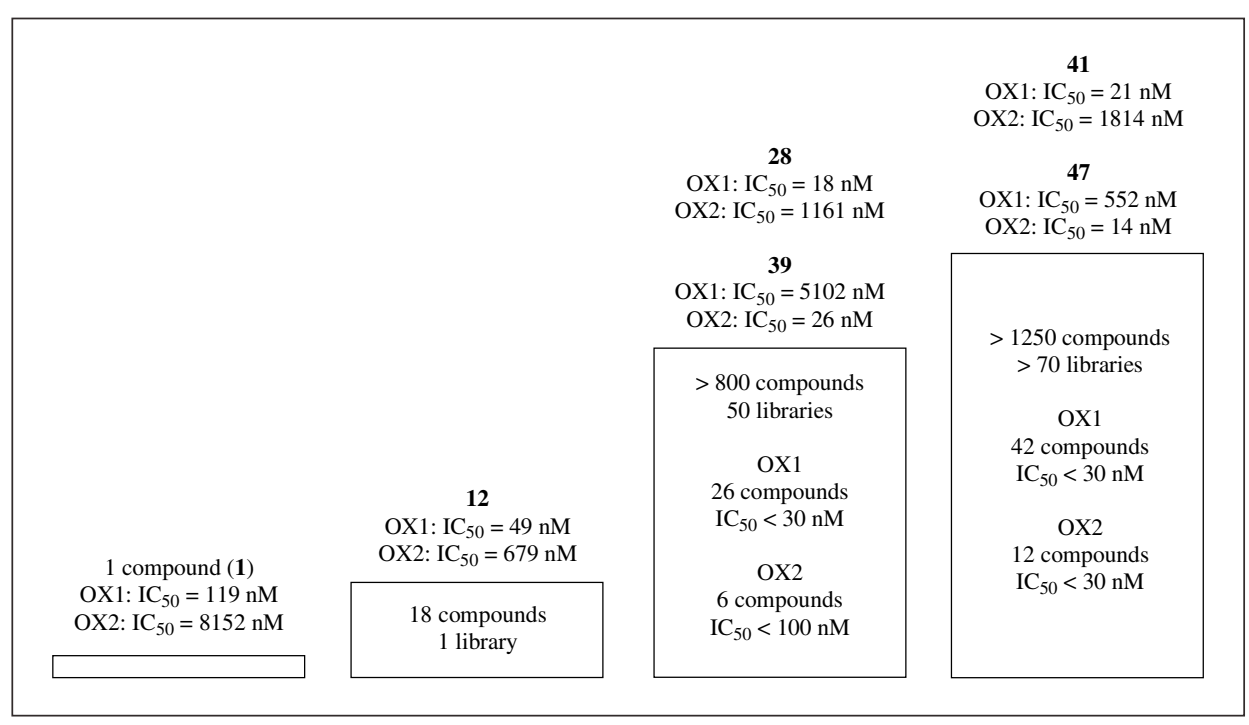

Scheme 3. Statistics - progress of the orexin receptor antagonist project

\subsection{Modification of the Amino Acid} Side Chain

To further expand this class of compounds substituents were introduced in the alpha-position of the glycine moiety of $\mathbf{1}$. Phenylglycine derivatives, as found in $\mathbf{4 1}$, could be substituted with alkyl amides (e.g. 42) and still exhibited high affinities, which was not the case in the glycine series (Table 4). Subsequently more than 200 analogues with modifications of the $\mathrm{R}^{1}$ - and $\mathrm{R}^{2}$-substituent were synthesized. High affinities towards either one of the two receptors as well as various selectivity profiles could be identified within this series. Naphthylmethyl-substitution in $\mathrm{R}^{1}$ furnished compounds with remarkable activities on both receptors (43 and $\mathbf{4 4}$ ), whereas compound 45 was selectively active on OX1. The phenethyl analogues 46 and 47 preferentially bound to OX2 with high affinity.

Some of the phenylglycine derivatives are well absorbed after oral application and cross the blood-brain barrier. Studies to further exploit this interesting class of molecules are currently ongoing.

\section{Conclusion}

We have demonstrated that a parallel chemistry approach can be successfully applied to optimize rapidly and efficiently properties of a compound class in a multidimensional way (Scheme 3). A first compound library finished only one month after project initiation already comprised a relatively high affinity compound $\left(\mathbf{1 2}, \mathrm{IC}_{50}=\right.$ $49 \mathrm{nM}$ ). During the first year more than 800 tetrahydroisoquinoline derivatives were synthesized in 50 libraries. Twenty-six compounds are highly active on $\mathrm{OX} 1\left(\mathrm{IC}_{50}<\right.$ $30 \mathrm{nM}$ ) whereas six were found showing affinities below $100 \mathrm{nM}$ on OX2. The most potent compounds at that time were 28 and 39.

Up to now more than 1250 tetrahydroisoquinolines have been prepared. During the last two years we could not only identify compounds highly selective and very potent on OX2 (12 compounds with $\mathrm{IC}_{50}<30 \mathrm{nM}$ ) but also optimize physicochemical and pharmacological properties at the same time. Simultaneously other classes of compounds were exploited in an analogous fashion. Results will be published elsewhere.

Received: March 25, 2003

[1] R.E. Dolle, J. Comb. Chem. 2002, 4, 369418.

[2] R.A. Goodnow, J. Cell. Biochem. Suppl. 2001, 37, 13-21. 
Table 4. Optimization of phenylglycine derivatives of compound 1<smiles>[R]NC(=O)C(c1ccccc1)N1CCc2cc(OC)c(OC)cc2C1[R7]</smiles>

\begin{tabular}{|c|c|c|c|c|}
\hline $\mathrm{R}^{1}$ & $\mathrm{R}^{2}$ & cpd & $\begin{array}{c}\text { OX1 } \\
\text { IC }_{50}[\mathrm{nM}]\end{array}$ & $\begin{array}{c}\mathrm{OX} 2 \\
\mathrm{IC}_{50}[\mathrm{nM}]\end{array}$ \\
\hline & & 41 & 21 & 1814 \\
\hline & & 42 & 75 & 1811 \\
\hline & & 43 & 8 & 109 \\
\hline & & 44 & 37 & 80 \\
\hline & & 45 & 45 & 1536 \\
\hline & & 46 & 1906 & 19 \\
\hline & & 47 & 552 & 14 \\
\hline
\end{tabular}

[3] a) H. An, P.D. Cook, Chem. Rev. 2000, 100,3311-3340; b) C.M. Baldino, J. Comb. Chem. 2000, 2, 89-103; c) L.M. Gayo, Biotechnol. Bioeng. (Comb. Chem.) 1998, 61, 95-106.

[4] W.J. Coates, D.J. Hunter, W.S. MacLachlan, Drug Discov. Today 2000, 5, 521-527.

[5] a) J. Everett, M. Gardner, F. Pullen, G.F. Smith, M. Snarey, N. Terrett, Drug Discov. Today 2001, 6, 779-785; b) R. Giger, Chimia 2000, 54, 37-40.

[6] ADME: Absorption, Distribution, Metabolism, Elimination.

[7] a) C. Edwards, D.J. Hunter, J. Comb. Chem. 2003, 5, 61-66; b) I. Hughes, D. Hunter, Curr. Opin. Chem. Biol. 2001, 5, 243-247; c) R.A. Tommasi, L.W. Whaley, H.R. Marepalli, J. Comb. Chem. 2000, 2, 447-449.

[8] a) L. De Lecea, T.S. Kilduff, C. Peyron, X.-B. Gao, P.E. Foye, P.E. Danielson, C. Fukuhara, E.L.F. Battenberg, V.T. Gautvik, F.S. Bartlett, W.N. Frankel, A.N. Van Den Pol, F.E. Bloom, K.M. Gautvik, J.G. Sutcliffe, Proc. Natl. Acad. Sci. USA 1998, 5, 322-327; b) T. Sakurai, A. Amemiya, M. Ishii, I. Matsuzaki, R.M. Chemelli, H. Tanaka, S.C. Williams, J.A. Richardson, G.P. Kozlowski, S. Wil- son, J.R. Arch, R.E. Buckingham, A.C. Haynes, S.A. Carr, R.S. Annan, D.E. McNulty, W.S. Liu, J.A. Terrett, N.A. Elshourbagy, D.J. Bergsma, M. Yanagisawa, Cell 1998, 92, 573-585.

[9] T.S. Kilduff, C. Peyron, Trends Neurosci. 2000, 23, 359-365.

[10] a) R.A. Porter, W.N. Chan, S. Coulton, A. Johns, M.S. Hadley, K. Widdowson, J.C. Jerman, S.J. Brough, M. Coldwell, D. Smart, F. Jewitt, P. Jeffrey, N. Austin, Bioorg. Med. Chem. Lett. 2001, 11, 1907-1910; b) C.L. Branch, W.N. Chan, A. Johns, C.N. Johnson, D.J. Nash, R. Novelli, J.-P. Pilleux, R.A. Porter, R.E.A. Stead, G. Stemp (SmithKline Beecham P.L.C.), WO 0302561 A1, 2003; c) W.N. Chan, A. Johns, C.N. Johnson, R. Novelli, R.A. Porter (SmithKline Beecham P.L.C.), WO 0302559 A2, 2003; d) C.L. Branch, S. Coulton, A. Johns, C.N. Johnson, R.A. Porter, G. Stemp, K. Thewlis (SmithKline Beecham P.L.C.), WO 0290355 A1, 2002; e) P. Gaillard, C.N. Johnson, R. Novelli, R.A. Porter, G. Stemp, K.M. Thewlis (SmithKline Beecham P.L.C.), WO 0289800 A2, 2002; f) H. Aissaoui, M. Clozel, T. Weller, R. Koberstein, T. Sifferlen, W. Fischli (Acte- lion Pharmaceuticals Ltd.), WO 0251838 A1, 2002; g) C.L. Branch, C.N. Johnson, A.B. Smith, G. Stemp, K. Thewlis (SmithKline Beecham P.L.C.), WO 0244172 A1, 2002; h) C.L. Branch, C.N. Johnson, G. Stemp, K. Thewlis (SmithKline Beecham P.L.C.), WO 0196302 A1, 2001; i) K. Yamada, M. Hirose, H. Iwaasa (Banyu Pharmaceutical Co., Ltd.), WO 0185693 A1, 2001; j) S. Coulton, A. Johns, R.A. Porter (SmithKline Beecham P.L.C.), WO 0047580 A2, 2000; k) S. Coulton, A. Johns, R.A. Porter (SmithKline Beecham P.L.C.), WO 0047577 A1, 2000; 1) A. Johns, R.A. Porter (SmithKline Beecham P.L.C.), WO 0047576 A1, 2000; m) A. Johns, R.A. Porter (SmithKline Beecham P.L.C.), WO 9958533 A1, 1999.

[11] FLIPR: Fluorescent Imaging Plate Reader

[12] D. Smart, J.C. Jerman, S.J. Brough, S.L. Rushton, P.R. Murdock, F. Jewitt, N.A. Elshourbagy, C.E. Ellis, D.N. Middlemiss, F. Brown, Brit. J. Pharmacol. 1999, 128, $1-3$.

[13] H. Aissaoui, M. Cappi, M. Clozel, W. Fischli, R. Koberstein (Actelion Pharmaceuticals Ltd.), WO 0168609 A1, 2001. 